\title{
Curriculum optimization of College of Optical Science and Engineering
}

Xiaoping Wang, Zhenrong Zheng, Kaiwei Wang, Xiaodong Zheng, Song Ye, et al.

Xiaoping Wang, Zhenrong Zheng, Kaiwei Wang, Xiaodong Zheng, Song Ye, Yuhui Zhu, "Curriculum optimization of College of Optical Science and Engineering," Proc. SPIE 10452, 14th Conference on Education and Training in Optics and Photonics: ETOP 2017, 104522J (16 August 2017); doi: 10.1117/12.2269879

Event: 14th Conference on Education and Training in Optics and Photonics, ETOP 2017, 2017, Hangzhou, China 


\title{
Curriculum Optimization of College of Optical Science and Engineering
}

\author{
Xiaoping Wang*, Zhenrong Zheng, Kaiwei Wang, Xiaodong Zheng, Song Ye, Yuhui Zhu \\ College of Optical Science and Engineering, Zhejiang University, Hangzhou 310027, P. R. China
}

\begin{abstract}
The optimized curriculum of College of Optical Science and Engineering is accomplished at Zhejiang University, based on new trends from both research and industry. The curriculum includes general courses, foundation courses such as mathematics and physics, major core courses, laboratory courses and several module courses. Module courses include optical system designing, optical telecommunication, imaging and vision, electronics and computer science, optoelectronic sensing and metrology, optical mechanics and materials, basics and extension. These curricula reflect the direction of latest researches and relates closely with optoelectronics. Therefore, students may combine flexibly compulsory courses with elective courses, and establish the personalized curriculum of "optoelectronics $+\mathrm{X}$ ", according to their individual strengths and preferences.
\end{abstract}

Key words: curriculum; “optoelectronics + X”; courses module

\section{INTRODUCTION}

Zhejiang University has long been holding the educational philosophy of "putting people foremost, cultivating allround competence in students, seeking the truth and pioneering new trails in search of excellence, and is committed to developing high-quality innovation talents and future leaders with an international perspective". Based on those beliefs, "knowledge-capability-quality" is determined as the training objective of College of Optical Science and Engineering.

\section{THE EDUCATIONAL PHILOSOPHY AND GUIDING IDEOLOGY OF THE SPECIALTY}

Holding Zhejiang University's educational philosophy of putting people foremost, cultivating all-round competence in students, seeking the truth and pioneering new trails in search of excellence, the cultivation objectives of the college is to develop high-quality innovation specialist and future leaders who are abundant with humanities, management, teamwork, modern scientific awareness, international vision, mathematical basis, major knowledge, practical ability and

\footnotetext{
*Xiaoping Wang, E-mail address: xpwang@zju.edu.cn.

14th Conference on Education and Training in Optics and Photonics: ETOP 2017, edited by Xu Liu,

Xi-Cheng Zhang, Proc. of SPIE Vol. 10452, 104522 · ( ) 2017 ICO, IEEE, OSA, SPIE

CCC code: $0277-786 X / 17 / \$ 18 \cdot$ doi: $10.1117 / 12.2269879$
} 
overall quality. The graduates are envisioned to be capable of taking frontier scientific research, technique development, and system integration in the field of photoelectric information science and engineering.

\section{CURRICULUM}

\subsection{Credit setting and distribution}

The required graduation overall credits are 150, including general courses, foundation courses, major courses, personalized courses and the 2nd, 3rd, 4th class.

The proportion of credits for each course is as follows.

Table.1 Credit setting and distribution of College of Optical Science and Engineering

\begin{tabular}{|c|c|c|c|c|c|}
\hline distribution & general courses & foundation courses & major courses & $\begin{array}{c}\text { personalized } \\
\text { courses }\end{array}$ & total \\
\hline credits & 42 & 42 & 56 & 10 & 150 \\
\hline proportion & $30 \%$ & $27 \%$ & $43 \%$ & & $100 \%$ \\
\hline
\end{tabular}

\subsection{Course composition}

\subsubsection{General courses}

General courses is a part of higher education, which is "a civilization and humanity education to create a great vision, a broad insight, and elegant spirit ". The general courses of Zhejiang University include history and culture, literature and art, communication and leadership, economics and society, science and research, etc. General courses are designed to promote the combination of students' scientific spirit and humanistic spirit, broaden their horizons, increase their knowledge, and enhance their cognitive thinking ability, humanistic accomplishment and comprehensive quality.

\subsubsection{Mathematical and physical courses and computer programming}

Strengthening the mathematical and physical basis is the embodiment of rule of "emphasizing foundation", which is the main way to cultivate students' scientific thinking, scientific research, scientific calculation and logical reasoning. Grasping programming ability is the essential skill for the contemporary students to solve complex problems with use computer tools.

\subsubsection{Introductory major courses}

The introductory major courses, including engineering mathematics, mechanical and electrical engineering training, circuit and electronic technology and other disciplines, provide a multi-disciplinary way of thinking, a variety of ways to 
analyze problems for students, so that students establish a broad knowledge base.

\subsubsection{Obligatory major courses of the specialty}

The Obligatory major courses mainly consists of applied optics, physical optics, optoelectronics, applied electrooptics Lab., and introduction to optoelectronics and information. These are most important and foundation courses of the college. They are not only the necessary skills for undergraduates, but also the basis of subsequent major learning and research.

\subsubsection{Elective major courses group 1}

It involves courses such as optical communication, optical detection and instrumentation, microcontrollers, computer programming, image, material etc. They reflect the integration of light, machine, electricity, computing, image, material, telecommunication and etc. We provide the knowledge of a number of disciplines for students, so that they have a broader space for development and employment.

\subsubsection{Elective courses group 2}

It includes an even diverse disciplines such as micro-nano optics, imaging, spectrum, sensing, vision, color, display, optical design, so that students become composite specialist with a broad knowledge structure, which creates the conditions for students to choose courses according to individual interests.

\subsubsection{Internship and practice}

Practical training is an indispensable part of higher education system, which is an important path to improve students' engineering ability and innovative spirit. The design courses and internship at factories, institutes and even overseas university cover from the first year to the third year provide a platform to cultivate students' ability to solve practical engineering problems using curriculum knowledge, practical innovation ability, scientific research ability and teamwork ability. 
Table.2 The Course composition of College of Optical Science and Engineering.

\begin{tabular}{|c|c|}
\hline $\begin{array}{l}\text { Internship } \\
\text { and Practice } \\
\text { (10 credits) }\end{array}$ & $\begin{array}{l}\text { Short terms(freshman sophomore and junior), graduation } \\
\text { design and thesis }\end{array}$ \\
\hline $\begin{array}{l}\text { Selective } \\
\text { Group } 2 \\
8 \text { credits from } \\
37.5 \text { ) } \\
\end{array}$ & $\begin{array}{c}\text { Optical design, Optical communication, Graphics and vision, } \\
\text { Electronics and computer, Opto-electronic sensors, } \\
\text { Optomechanical and materials engineering }\end{array}$ \\
\hline $\begin{array}{l}\text { Selective } \\
\text { Group } 1 \\
\text { (13 credits } \\
\text { from } 27 \text { ) } \\
\end{array}$ & $\begin{array}{l}\text { Computer software(3), Electro-magnetic wave(2.5), Signal and } \\
\text { systems(3), Microprocessor and interface(3.5), Quantum optics (2.5), } \\
\text { Opto-electronic material(2.5), Opto-electric detection(3), Computer } \\
\text { vision(3),Fiber communication(2.5),Fiber communication Lab(1.5) }\end{array}$ \\
\hline $\begin{array}{l}\text { Obligatory } \\
\text { course } \\
\text { (17 credits) }\end{array}$ & $\begin{array}{l}\text { Applied optics (4),Physical optics(5), Optoelectronics(3), Applied } \\
\text { electro-optics Lab.(2.5), Introduction to optoelectronics and } \\
\text { information(1), Literature review and writing(1.5) }\end{array}$ \\
\hline $\begin{array}{l}\text { Foundation } \\
\text { course } \\
\text { ( } 22 \text { credits) }\end{array}$ & $\begin{array}{l}\text { Ordinary Differential equation(1); Partial differential equation(2), } \\
\text { Complex variable function(1.5), probability and statistics(2.5), } \\
\text { digital electronics(2.5), Engineering graphics(2.5), etc. }\end{array}$ \\
\hline
\end{tabular}

\subsection{Course content and module}

Optical engineering is a frontier discipline that integrates optics, mechanics, electronics and computer science. According to the interdisciplinary characteristics of optics, mechanics, electronics, computer science, imaging, control and telecommunication, the course system is based on the general courses, mathematical and physical foundation courses and major core courses. The course system is adapted to the development of discipline and represents the latest orientation of research, which includes courses of information, computer science, image, material etc. Several course modules (tracks ) are established and are ready to be selected by students . Students can combine personal expertise and interest, through compulsory and flexible elective courses, to form a personalized "photo-electrics $+\mathrm{X}$ " course, so that they have a broader space for development.

Course modules: Compulsory "mathematical + major basis", "experimental skills", "practice", elective "optical system design", "optical communication", "image and vision", "electronic and computer science", "photoelectric sensing and detection ", " machine and material", and interdisciplinary personalized courses. For instance:

Combination 1: Engineering drawing + Experiment + Machine design (the summer of the $1^{\text {st }}$ year);

Combination 2: Applied optics + Applied optics experiment + Optical system design (the summer of the $2^{\text {nd }}$ year);

Combination 3: Circuit, Analog and digital electronics + Experiment + Microcontroller and interface + Microcontroller 
experiment + Microcontroller system design (the summer of the $2^{\text {nd }}$ year);

Combination 4: Electromagnetic wave theory + Physical optics + Physical optics experiment;

Combination 5: Photoelectric detection and optoelectronics + Photoelectric application experiment (photoelectric design competition);

Combination 6: Optical communication technology + Optical communication experiment.

\section{ANALYSIS OF THE CHARACTERISTICS OF TRAINING PROGRAMS}

$>$ Curriculum is decomposed into three main lines, i.e., optics, mechanics + material science, and electronics + computer science + signal processing. Surrounding the core courses of optical engineering, supplemented courses of mechanical drawing + optical machine structure design (software design $+3 \mathrm{D}$ printing + assembly and test) are established. A complete, measurable optical system design will be established. At the same time, in the line of electronics + computer science + signal processing, there are electronic courses tailored for optical engineering, strengthening the programing skill and application, so that optoelectronic devices / systems can be equipped with intelligent control.

$>$ Emphasizing foundation. Strengthen the teaching of specialized courses and physics: set the course of "electromagnetic field and electromagnetic wave", the formation of physical physics from the University of electromagnetic physics optical system, designed to build bridges to the optical branch, so that major courses based on the physical image, To provide the necessary conditions for the cultivation of innovative specialist.

Enhancing practice. In the major courses, a number of "Theory (T) + Laboratory (L) + Design (D)" combination modules are set up, including "Applied Optics + Applied Optics Experiment + Optical System Design", "Physical Optics + Physical Optics Experiment + Optical Experiment", "Photoelectric detection + Optoelectronics + Photoelectric experiment + Photoelectric system design", "Optical communication technology + Optical communication experiment + Optical fiber communication course design", and "Microcomputer principle and interface technology + Computer experiment + Computer system design ", which fully strengthen the interactive teaching process that connects theory and practice; The new course " Design of optical mechanical structure" lets students to deepen knowledge of engineering drawing and computer-aided design software in the optical structure 
design applications. "Electronic system design" is to improve the capacity of designing electronic circuits and systems, using analog circuits and digital circuit technology. The credits of extracurricular practice activities (such as photoelectric design competition, research family, etc.) allow students to have the opportunity to test and consolidate the theoretical knowledge in the experiment, design and practice of both inside and outside the class.

$>$ According to the research interests of professors, 22 elective courses in various fields are set up, including theoretical basis courses such as signal and system, digital signal processing, technical courses such as spectrum technology and application, laser technology and application, visual information application, etc, further in-depth courses on the basis of obligatory courses such as integrated optoelectronic devices and design, precision interference sensing technology and applications, as well as much courses that open up students vision, such as light quantum science, bio-photonics, color information engineering. The major curriculum extends the modern physics and optics-related interdisciplinary disciplines to the field of optical engineering.

\section{ANALYSIS OF RATIONALITY OF TRAINING PROGRAM}

\subsection{The degree of compliance with the training goals}

First of all, the training program should be adapted to the position of research university and the overall training program of whole university. To cultivate graduates with "knowledge-ability-quality", we should implement the strategy of improving quality of general courses, major courses and major courses. The general curriculum focuses on the improvement of the comprehensive quality of the students, providing students with a variety of ways of thinking, to enhance students' cognitive ability and comprehensive quality. The major courses focus on establishing a broad subject knowledge and lay the foundation for the development of students' professional skills. Major courses focus on training students a solid professional knowledge and practice, innovation and other comprehensive ability.

The training programs must adapt to training goals. The training goal of Optical Science and Engineering is to cultivate one who has a solid mathematical foundation, a solid major knowledge, the spirit of innovation and practical ability, who comprehensively develops in moral, intellectual, physical, beauty, who has international competitiveness in the field of optoelectronic information engineering, after the multi-disciplinary general courses, engineering category education, professional education and practical education. So that it requires the curriculum wide, specialized and cross, 
and the course contents fine and deep. The general curriculum requires students to have knowledge of humanities, social sciences, economics and other disciplines, which reflects the "cross" of the course system; The foundation course of mathematics, as well as engineering mathematics, electronic technology, engineering drawing, computer technology , aims to make students to lay a solid foundation of mathematical, electrical, mechanical and technical basis, reflecting the curriculum's "wide"; Three major optical core courses, which requires students to have a solid knowledge of optical engineering disciplines, reflects the curriculum "specialized". In addition, it involves the optional elective courses of light, machine, electricity, calculation, image and material, as well as optional elective courses related to several fields of optical engineering, which provides students with opportunities to self-built "photoelectric $+\mathrm{X}$ " personalized training program combined with personal expertise and hobbies.

The practical teaching, including experimental courses, comprehensive practical courses, 3 summer internships and graduation design, has 29 credits, accounting for $23 \%$ of the total credits, which is a large proportion; This can definitely enhance students' innovation ability.

\subsection{Comparison with counterpart universities}

For the rationality of the training program, we compare it with the educational programs and curriculum of the optical science and engineering disciplines of the University of Arizona ${ }^{[4]}$ and the University of Rochester ${ }^{[5]}$.

1) Comparison of general, foundation and major courses

Table 3. Comparison of general courses, major class and major courses between ZJU and counterparts

\begin{tabular}{|c|c|c|c|c|c|c|}
\hline University & Course & General & Foundation & Major & Personalized & Total \\
\hline \multirow{2}{*}{ ZJU } & Credits & 42 & 42 & 56 & 10 & 150 \\
\cline { 2 - 7 } & Ratio & $30 \%$ & $27 \%$ & $43 \%$ & & $100 \%$ \\
\hline \multirow{2}{*}{ Arizona } & Credits & 24 & 45 & 42 & 18 & 129 \\
\cline { 2 - 7 } & Ratio & $20 \%$ & $31 \%$ & $49 \%$ & & $100 \%$ \\
\hline \multirow{2}{*}{ Rochester } & Credits & 32 & 44 & 46 & & 122 \\
\cline { 2 - 7 } & Ratio & $26 \%$ & $36 \%$ & $38 \%$ & & $100 \%$ \\
\hline
\end{tabular}




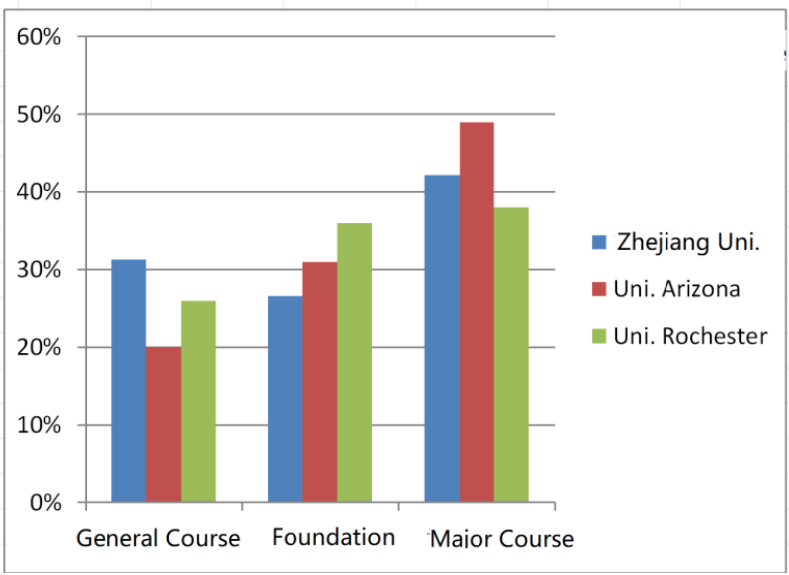

Figure 1. Comparison of general courses, major class and major courses between ZJU and counterparts

As the ideological and political courses occupy a certain degree of credits, so the proportion of general courses in Zhejiang University is the highest; The ratio of foundation classes is a little lower, but the amount of credits is the same as the other two universities; Major courses' credit is the highest, for the reason that ZJU sets more engineering application courses.

2) Comparison of compulsory courses (including experimental and design courses), elective courses, Laborotory credits

Table 4. Comparison of major compulsory course, major elective course and practice teaching between ZJU and counterparts

\begin{tabular}{|c|c|c|c|c|}
\hline University & $\begin{array}{c}\text { Major } \\
\text { compulsory course }\end{array}$ & $\begin{array}{c}\text { Major } \\
\text { elective course }\end{array}$ & Laboratory & Total \\
\hline ZJU & 35.5 & 14 & 18 & 67.5 \\
\hline Arizona & 32 & 19 & 7 & 58 \\
\hline Rochester & 32 & 8 & 6 & 46 \\
\hline
\end{tabular}

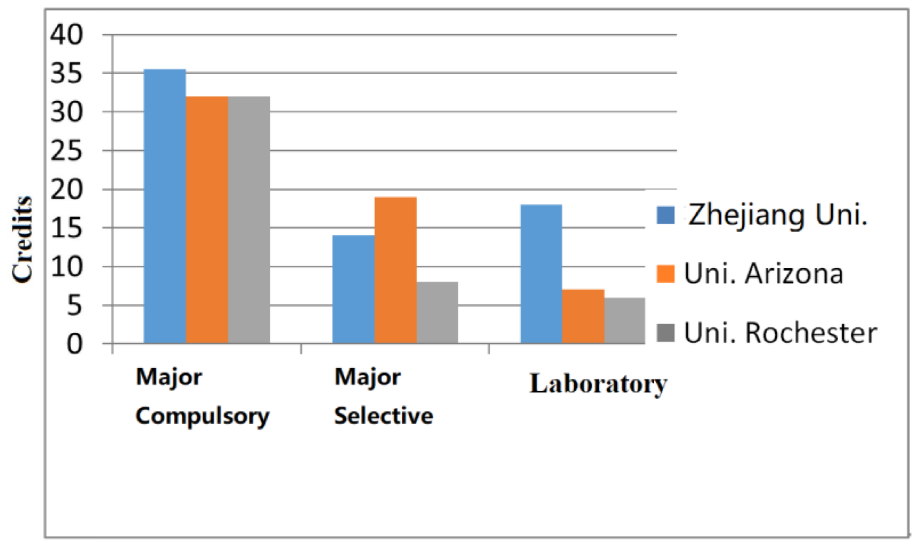

Figure 2. Comparison of major compulsory course, major elective course and practice teaching between ZJU and counterparts 
It could be seen that Zhejiang University has set much more laboratory and practical courses than foreign universities, which is in line with China's engineering university training goals to provide engineering and application specialist for the community.

Compared with the counterpart's foundation courses and major courses, one can see that optical foundation courses have a great proportion, such as the application of optics, physical optics and optoelectronics. Differences are list as follows: 1) Zhejiang University's compulsory courses have a certain percentage of information courses, which embodies the characteristics of information engineering categories. Meanwhile the University of Arizona optical science aims at training specialized optical talent of a science degree. So there are such differences in the major curriculum. 2) Zhejiang University's major elective courses are multi-directional, such as color, display, imaging, spectrum, sensing, computer applications and others, but with small credits, hoping that graduates can become composite specialist with a broad knowledge structure. But the University of Arizona's major elective courses have a clear direction with heavy credits, and the knowledge structure is relatively concentrated.

\section{CONCLUSION}

The new trends from both research and industry required a rethink and redesign on the curriculum of College of Optical Science and Engineering is accomplished at Zhejiang University. New courses such as computer vision and applied opto-electronics laboratory have been introduced. These alterations reflect the direction of latest researches progress and relates closely with nano optics, optoelectronics, and automatic optical inspection demanded from the Industrial 4.0. Students may combine flexibly compulsory courses with elective courses, and establish the personalized curriculum according to their individual interest. 